\title{
Mouth pressure in response to magnetic stimulation of the phrenic nerves
}

Carl-Hugo Hamnegård, Simon Wragg, Dimitris Kyroussis, Gary Mills, Björn Bake, Malcolm Green, John Moxham

\begin{abstract}
Background - Diaphragm strength can be assessed by the measurement of gastric (Tw PGA), oesophageal (Tw POES), and transdiaphragmatic (Tw PDI) pressure in response to phrenic nerve stimulation. However, this requires the passage of two balloon catheters. A less invasive method of assessing diaphragm contractility during stimulation of the phrenic nerves would be of clinical value. A study was undertaken to determine whether pressure measured at the mouth (Tw PM) during magnetic stimulation of the phrenic nerves accurately reflects Tw POES, and to investigate the relations between TW PM and TW PDI; and also to see whether glottic closure and twitch potentiation can be avoided during these measurements.

Methods - Eight normal subjects and eight patients with suspected respiratory muscle weakness without lung disease were studied. To prevent glottic closure magnetic stimulation of the phrenic nerves was performed at functional residual capacity during a gentle expiratory effort against an occluded airway incorporating a small leak. Tw PDI, Tw PoEs, and Tw PM were recorded. Care was taken to avoid potentiation of the diaphragm.
\end{abstract}

Results - In normal subjects mean Tw PM was $13 \cdot 7 \mathrm{~cm} \mathrm{H}_{2} \mathrm{O}$ (range 11.3-16.1) and $\mathrm{TW}$ POES was $13 \cdot 3 \mathrm{~cm} \mathrm{H}_{2} \mathrm{O}$ (range $10 \cdot 4-15 \cdot 9$ ) with a mean (SD) difference of $0.4(0.81)$ cm $\mathrm{H}_{2} O$. In patients mean $\mathrm{Tw} P M$ was $9 \cdot 1 \mathrm{~cm} \mathrm{H}_{2} \mathrm{O}$ (range $0 \cdot 5-18 \cdot 2$ ) and TW POES was $9 \cdot 3$ (range $0 \cdot 7-18 \cdot 7$ ) with a mean (SD) difference of $-0.2(0.84) \mathrm{cm} \mathrm{H}_{2} \mathrm{O}$. The relation between TW PM and TW PDI was less close but was well described by a linear function. In patients with diaphragm weakness (low sniff PDI) Tw PM was $<10 \mathrm{~cm} \mathrm{H}_{2} \mathrm{O}$.

Conclusions - TW PM reliably reflects Tw POES and can be used to predict TW PDI in normal subjects and patients without lung disease. TW PM may therefore be a promising non-invasive, non-volitional technique for the assessment of diaphragm strength.

(Thorax 1995;50:620-624)

Keywords: twitch mouth pressure, respiratory muscle strength, magnetic stimulation.

Diaphragm strength can be assessed by measurements of oesophageal (Tw PoEs), gastric (Tw PGA), and transdiaphragmatic (Tw PDI) pressure in response to phrenic nerve stimulation. ${ }^{12}$ This assessment has the advantage of not being dependent on the effort and cooperation of the subject and therefore provides an objective estimation of diaphragm contractility. The requirement for two balloon catheters, one positioned in the oesophagus and the other in the stomach, limits the clinical application of this method. It is known that changes in mouth pressure accurately reflect pleural pressure under isovolumetric conditions providing the time constant for equilibration of alveolar and mouth pressure is sufficiently short and the glottis remains open. ${ }^{3}$ Yan et al have measured mouth pressures during electrical phrenic nerve stimulation in normal volunteers. ${ }^{4}$ To avoid glottic closure the subjects inspired to total lung capacity (TLC) and then exhaled passively through an expiratory resistance from TLC to functional residual capacity (FRC) whilst the phrenic nerves were electrically stimulated. This technique is difficult to apply to patients and the inspiratory effort potentiates the diaphragm twitch pressure. ${ }^{5}$

Although bilateral electrical stimulation of the phrenic nerves has been used successfully in normal subjects to study diaphragm function it has limitations in a clinical setting. Electrical stimulation is often uncomfortable, particularly when attempts are made to achieve bilateral supramaximal stimulation. Furthermore, during repeated attempts to stimulate electrically the phrenic nerves it is difficult to avoid diaphragm twitch potentiation. In a previous study we showed that a maximal voluntary diaphragmatic contraction could increase Tw PDI by up to $70 \% .^{5}$

The technique of magnetic stimulation of the phrenic nerve roots has been reported to have advantages over electrical stimulation. ${ }^{67}$ It is easily applied, well tolerated and reproducible, and therefore suitable for the sequential assessment of diaphragm contractility in both normal subjects and patients. ${ }^{7}$

The purpose of this study was to investigate the relation between mouth pressure and POES and PDI during magnetic stimulation of the phrenic nerve roots in normal subjects and patients whilst keeping the glottis open and avoiding potentiation of the diaphragm.

\section{Methods}

STUDY POPULATION

Eight normal men and eight male patients without lung disease referred for investigation of possible respiratory muscle weakness were 
Vital capacity (VC), mean (SD) twitch mouth (TW PM), oesophageal (TW POES), and transdiaphragmatic (Tw PDI) pressures and maximum sniff transdiaphragmatic pressures (sniff PDI) in eight normal subjects and eight patients

\begin{tabular}{|c|c|c|c|c|c|c|c|}
\hline Subject & Age (years) & $V C$ (\% pred) & $T w P_{M}\left(\mathrm{~cm} \mathrm{H}_{2} \mathrm{O}\right)$ & TW POES $\left(\mathrm{cm} \mathrm{H}_{2} \mathrm{O}\right)$ & $T_{W} P D I\left(\mathrm{~cm} \mathrm{H}_{2} \mathrm{O}\right)$ & Sniff $P D I\left(\mathrm{~cm} \mathrm{H}_{2} \mathrm{O}\right)$ & Diagnosis \\
\hline $\begin{array}{l}1 \\
2 \\
3 \\
4 \\
5 \\
6 \\
6 \\
7 \\
8\end{array}$ & $\begin{array}{l}32 \\
33 \\
38 \\
39 \\
38 \\
45 \\
54 \\
31\end{array}$ & $\begin{array}{r}122 \\
88 \\
111 \\
114 \\
109 \\
114 \\
102 \\
100\end{array}$ & $\begin{array}{l}15 \cdot 1(0.6) \\
16 \cdot 1(0.7) \\
12.6(0.5) \\
13.0(1.2) \\
10.5(1.1) \\
14.0(0.5) \\
15.1(2.6) \\
12.5(0.2)\end{array}$ & $\begin{array}{r}14.2(1.1) \\
15.9(0.4) \\
11.9(0.5) \\
11.9(1.1) \\
9.8(0.9) \\
14.6(0.4) \\
14.1(2.1) \\
13.5(1.5)\end{array}$ & $\begin{array}{l}27 \cdot 0(0.4) \\
32.5(1 \cdot 1) \\
24.9(1.0) \\
34.0(1.7) \\
17.9(1 \cdot 2) \\
30.3(0.7) \\
34 \cdot 1(3.6) \\
27.4(1.2)\end{array}$ & $\begin{array}{l}150 \\
155 \\
146 \\
144 \\
167 \\
153 \\
138 \\
129\end{array}$ & \\
\hline $\begin{array}{r}9 \\
10 \\
11 \\
12 \\
13 \\
14 \\
15 \\
16\end{array}$ & $\begin{array}{l}55 \\
44 \\
61 \\
60 \\
42 \\
23 \\
41 \\
47\end{array}$ & $\begin{array}{r}100 \\
76 \\
78 \\
94 \\
63 \\
41 \\
62 \\
36\end{array}$ & $\begin{array}{r}18.2(0.8) \\
11.6(0.8) \\
16.6(1.6) \\
8.6(0.4) \\
5.9(0.2) \\
6.0(2.1) \\
5.8(1.8) \\
0.5(0.5)\end{array}$ & $\begin{array}{r}18.7(2.0) \\
10.8(1.0) \\
16.1(1.9) \\
8 \cdot 1(0.4) \\
7.2(0.6) \\
5.8(1.9) \\
7.3(2.8) \\
0.5(0.6)\end{array}$ & $\begin{array}{r}29.6(1.5) \\
19.9(3.0) \\
31.7(2.6) \\
16.0(0.4) \\
12.8(1.0) \\
14.0(0.7) \\
10.1(2.7) \\
0.9(0.8)\end{array}$ & $\begin{array}{r}99 \\
122 \\
100 \\
40 \\
54 \\
59 \\
68 \\
8\end{array}$ & $\begin{array}{l}\text { Assessment of dyspnoea } \\
\text { Assessment of dyspnoea } \\
\text { Assessment of dyspnoea } \\
\text { Right hemidiaphragm paresis } \\
\text { Right hemidiaphragm paresis } \\
\text { Right hemidiaphragm paresis } \\
\text { Left hemidiaphragm paresis } \\
\text { Bilateral diaphragm paralysis }\end{array}$ \\
\hline
\end{tabular}

studied. The normal subjects were familiar with the goals of the investigation and had previously participated in studies of respiratory system mechanics. All participants gave their informed consent and the protocol was approved by the hospital ethics committee.

\section{MEASUREMENTS}

Mouth pressure (Рм) was measured using a mouthpiece which could be occluded at the distal end with a valve, leaving a small leak to prevent glottic closure during inspiratory or expiratory manoeuvres. ${ }^{8}$ Gastric (PGA) and oesophageal (PoEs) pressures were recorded by conventional balloon catheter systems (PK Morgan, Rainham, Kent, UK). The balloons were positioned in the oesophagus $10 \mathrm{~cm}$ above the cardia and in the stomach. They were filled with 0.5 and $2.0 \mathrm{ml}$ of air, respectively. The position of the oesophageal balloon was adjusted until changes in transpulmonary pressure ( $\mathrm{PM}$ - POEs) were less than $2 \mathrm{~cm} \mathrm{H}_{2} \mathrm{O}$ during inspiratory manoeuvres against an occluded airway. ${ }^{9}$ Tw PM, Tw PoEs, and Tw PGA were defined as the difference between baseline pressures immediately before the twitch and the peak pressures during phrenic stimulation.

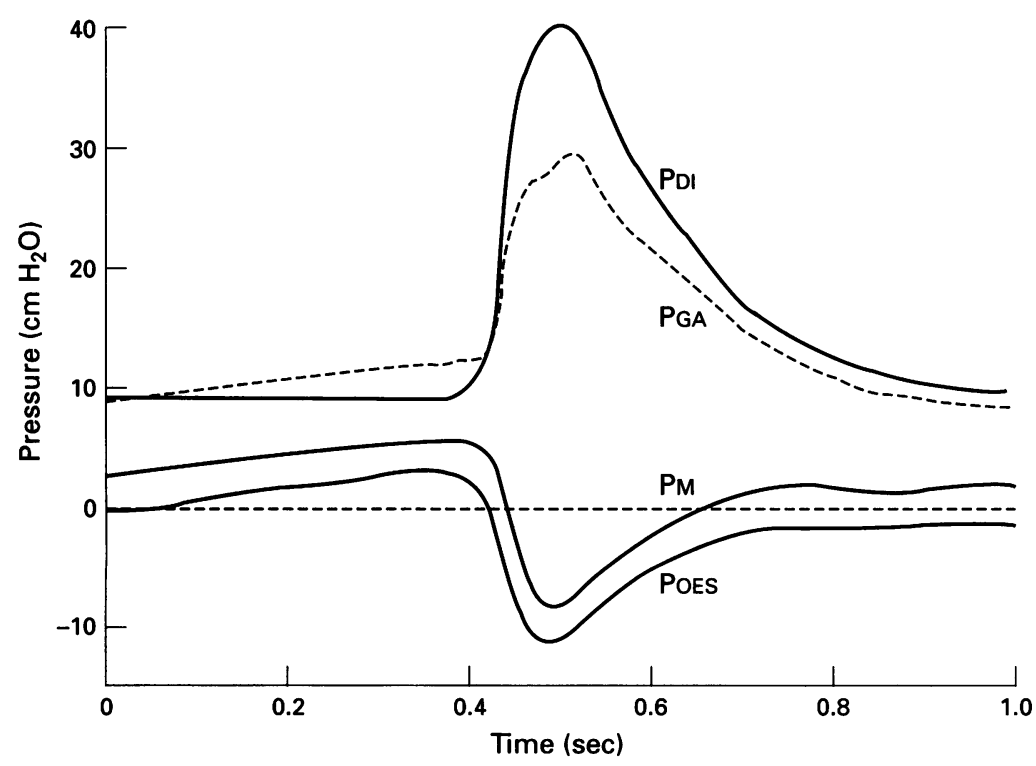

Figure 1 Mouth (PM), oesophageal (POES), gastric (PGA), and transdiaphragmatic (PDI) pressures during magnetic stimulation of the phrenic nerves of a normal subject at functional residual capacity during a gentle expiratory effort against an occluded mouthpiece. The magnetic stimulation was triggered when $\mathrm{PM}$ reached $+5 \mathrm{~cm} \mathrm{H}_{2} \mathrm{O}$.
PDI was calculated as the difference between PGA and PoEs.

\section{PHRENIC NERVE STIMULATION}

The phrenic nerve roots were bilaterally stimulated with cervical magnetic stimulation using a Magstim 200 (Magstim Co Ltd, Whitland, Dyfed, UK) and a circular $90 \mathrm{~mm}$ coil $(\mathrm{P} / \mathrm{N}$ 9784-00). ${ }^{10}$ To optimise the position of the coil the neck was flexed and several stimulations were performed over the spinous processes at varying levels in the midline between $\mathrm{C5}$ and C7 until the level was determined at which the maximum response could be elicited. Thereafter all stimulations were performed in that position and at full magnetic output. To avoid twitch on twitch potentiation the stimulations were performed 30 seconds apart.

\section{STUDY DESIGN}

Before any measurements were made the subjects were asked to rest quietly for at least 20 minutes. During the study the subjects were asked to breathe gently, to avoid deep inspirations and remain silent. At FRC the valve was closed and the subject asked to perform a gentle expiratory effort. The magnetic stimulation was triggered automatically when the mouth pressure reached $+5 \mathrm{~cm} \mathrm{H}_{2} \mathrm{O}$. This method was adopted to avoid glottic closure. The pressure of $5 \mathrm{~cm} \mathrm{H}_{2} \mathrm{O}$ was chosen to avoid triggering during normal breathing through the mouthpiece. The measurements were repeated five times. To ensure that the use of the mouthpiece or the expiratory manoeuvre did not significantly alter transdiaphragmatic pressure, five control twitch PDI values at relaxed FRC were obtained without the mouthpiece. When all the measurements had been made, maximal sniff PDI was determined. ${ }^{11}$

\section{SIGNAL PROCESSING AND ANALYSIS}

Pressures were measured by Validyne MP45 transducers $\left( \pm 150 \mathrm{~cm} \mathrm{H}_{2} \mathrm{O}\right)$ and amplified by Validyne carrier amplifiers (Validyne Corporation, Northridge, California, USA). These were calibrated before each study with a Universal Pressure Meter (Bio-Tek Instruments Inc, USA) which was regularly tested for accuracy with a water manometer. ${ }^{12}$ The signals were passed to a 12-bit NB-MIO-16 analog- 

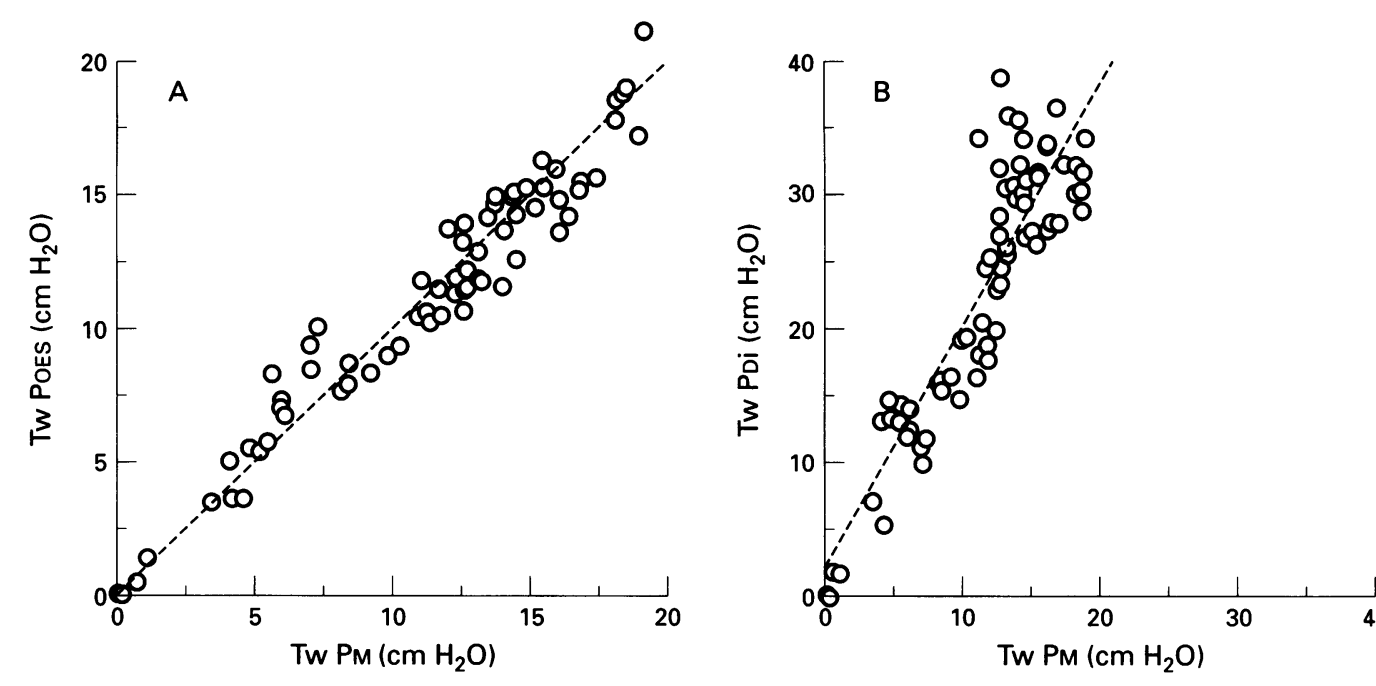

Figure 2 (A) Twitch mouth (TW PM) versus twitch oesophageal (TW POES) pressure in response to magnetic stimulation of the phrenic nerves including all data points $(n=80)$ from eight normal subjects and eight patients. The line of identity is dashed. Regression equation: TW POES $=0.6+0.94 \times T W P_{M}(r=0.97)$. (B) Twitch mouth (Tw PM) versus twitch transdiaphragmatic (TW PDI) pressure as in (A). The regression line is dashed: $T W P D I=2 \cdot 0+1 \cdot 82 \times$ $T W P M(r=0 \cdot 91)$.

digital board within a Macintosh Centris 650 computer (Apple Computer Inc, Cupertino, California, USA) where the information was recorded and analysed using LabVIEW® 2.2 software (National Instruments, Austin, Texas, USA). All pressure signals were sampled at $100 \mathrm{~Hz}$. Twitches were accepted for further analysis when they were (1) performed at FRC as judged by the end expiratory PoEs before the expiratory effort; and (2) superimposed on a relaxed diaphragm as judged by the absence of any increase in PDI compared with baseline.

\section{STATISTICAL ANALYSIS}

The statistical analysis was performed using StatView 4.0 (Abacus Concepts Inc, Berkeley, California, USA). Standard linear regression

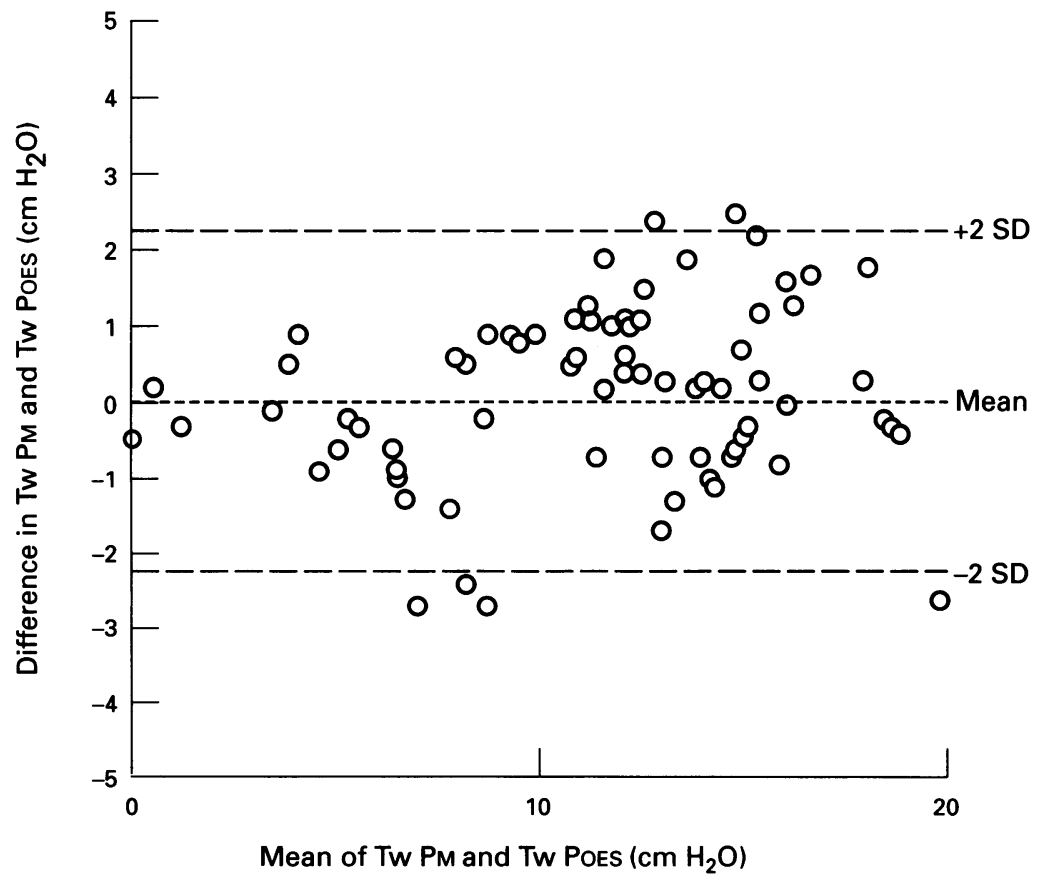

Figure 3 Bland-Altman plot of the difference between TW PM and TW POES and the mean values, with the limits of agreement. techniques, unpaired single $t$ test, and Bland $\stackrel{\circ}{2}$

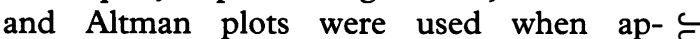
propriate. ${ }^{13} \mathrm{p}$ values of $<0.05$ were considered $\stackrel{\overline{\mathrm{D}}}{\mathrm{T}}$ statistically significant.

\section{Results}

The characteristics and pressures of the normal subjects and patients are detailed in the table. Figure 1 shows a typical example of the pressure recordings during magnetic stimulation of the phrenic nerves and illustrates the similarity between Tw PM and Tw PoEs.

The mean values of five single stimulations in each individual were analysed. In normal subjects mean Tw $\mathrm{PM}$ was $13.7 \mathrm{~cm} \mathrm{H}_{2} \mathrm{O}$ (range 11.3-16.1) and $\mathrm{Tw}$ Poes was $13.3 \mathrm{~cm} \mathrm{H}_{2} \mathrm{O} \stackrel{2}{2}$ (range 10.4-15.9), with a mean (SD) difference of $0.4(0.81) \mathrm{cm} \mathrm{H}_{2} \mathrm{O}$. In patients the mean Tw $\mathrm{PM}_{\mathrm{M}}$ was $9 \cdot 1 \mathrm{~cm} \mathrm{H}_{2} \mathrm{O}$ (range $0 \cdot 5-18 \cdot 2$ ) and $\mathrm{Tw} \delta$ PoEs was 9.3 (range $0.7-18.7$ ) with a mean difference of $-0 \cdot 2(0.84) \mathrm{cm} \mathrm{H}_{2} \mathrm{O}$. Five of the 옥 patients had Tw $\mathrm{PM}_{\mathrm{M}}<10 \mathrm{~cm} \mathrm{H}_{2} \mathrm{O}$.

The relation between Tw PM and Tw PoEs for five twitches in each of the 16 individuals $N$ in the study is shown in fig $2 \mathrm{~A}$. The pressures are closely distributed around the line of identity. The corresponding plot of Tw PM and Tw PDI is shown in fig 2B. The scatter is rather greater and TW PDI amplitude is approximately twice Tw PM. Comparison between all Tw PM values and Tw PoEs showed a mean (SD) 0 difference of $0 \cdot 1(1 \cdot 13) \mathrm{cm} \mathrm{H}_{2} \mathrm{O}(n=80)$. Fig- $\overline{0}$ ure 3 shows a Bland and Altman plot of the difference between Tw PM and Tw PoEs and $\mathbb{D}$ the mean, with the limits of agreement.

There was no significant difference between Tw PDI without a mouthpiece and when a mouthpiece was used, and a $5 \mathrm{~cm} \mathrm{H}_{2} \mathrm{O}$ expiratory pressure was produced (mean difference $0.6 \mathrm{~cm} \mathrm{H}_{2} \mathrm{O} ; \mathrm{p}=\mathrm{NS} ; \mathrm{n}=16$; unpaired $t$ test).

The mean (SD) sniff PDI for the normal subjects was $148(11.5) \mathrm{cm} \mathrm{H}_{2} \mathrm{O}$ and $69(37 \cdot 1) \mathrm{cm} \mathrm{H}_{2} \mathrm{O}$ for the patients. Figure 4 illustrates the relation between mean values 


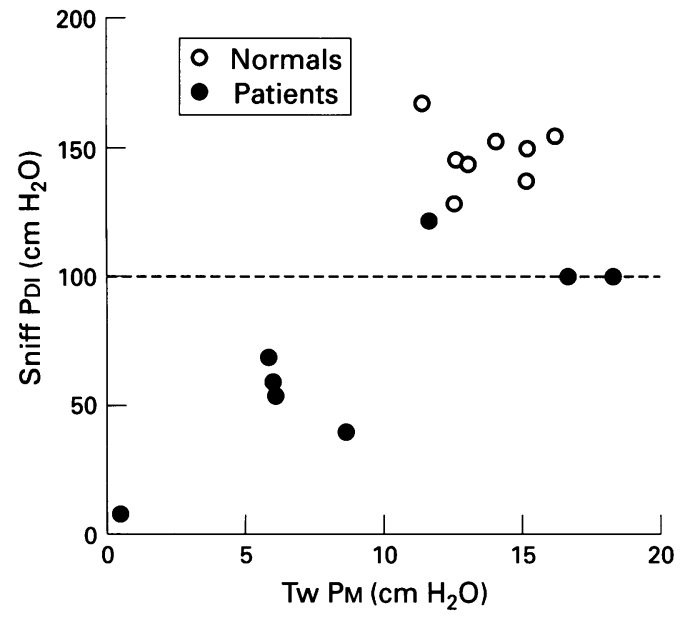

Figure 4 Transdiaphragmatic pressure during a maximal sniff manoeuvre (sniff PDI) compared with twitch mouth pressure (TW PM). Data from eight normal subjects (O) and eight patients (O). The dashed line indicates the normal lower limit of sniff PDI for men. ${ }^{11}$

$(n=5)$ of Tw PM and maximal sniff transdiaphragmatic pressure (sniff PDI) in each individual.

\section{Discussion}

We have found that by measuring pressure at the mouth during magnetic stimulation of the phrenic nerves diaphragm contractility can be assessed. The technique described avoids glottic closure and does not produce twitch potentiation.

The relation between Tw PM and Tw PoEs was close to unity with a mean (SD) difference of $0 \cdot 1(1 \cdot 13) \mathrm{cm} \mathrm{H}_{2} \mathrm{O}$. The regression equation between all Tw PM and Tw PoEs values had a slope close to unity and an intercept close to zero $(r=0.97)$. Thus Tw PM was found not only to be closely related to Tw PoEs, but also to be of equal magnitude. When Tw PM was compared with Tw PDI the degree of agreement decreased due to the combined variation seen in Tw Poes and Tw PGA. However, the relationship was well described by a linear function $(r=0.91)$.

Cervical magnetic stimulation was well tolerated by the normal subjects and the patients, and allowed diaphragm contractility to be easily and repeatedly studied. The magnitude of Tw PDI, Tw POES, and Tw PM is heavily dependent on diaphragm potentiation. ${ }^{514}$ Following a maximal inspiratory effort Tw PDI can increase by up to $70 \%$. The variability of $\mathrm{Tw} P M$ is likely to be large if potentiation is not avoided. The ease with which the phrenic nerves can be magnetically stimulated facilitates relaxation of the subject and minimises the number of phrenic nerve stimulations, thereby avoiding potentiation.

The relation between Tw PM and Tw PoEs has previously been studied ${ }^{415}$ but in circumstances where twitch potentiation or glottic closure were likely. Similowski et $a l^{6}$ looked at the relation between Tw PM and Tw PoEs during graded inspiratory efforts that would have produced twitch potentiation. They also studied Tw PM at relaxed FRC but found a poor relation between Tw PoEs and Tw PM. Yan et $a l^{4}$ recorded Tw $\mathrm{PM}$ in response to electrical phrenic nerve stimulation. To avoid glottic closure they studied subjects during passive deflation from TLC to FRC through an expiratory resistance. Inspiration to TLC must cause twitch potentiation and, furthermore, the procedure detailed in the study would be difficult to apply to patients.

Closure of the glottis is always a potential problem when measuring static respiratory pressures at the mouth. In the present study this problem was avoided by a gentle expiratory effort against a closed valve incorporating a small leak, thereby keeping the glottis open. ${ }^{7}$ The magnetic stimulation was triggered automatically when the mouth pressure reached $+5 \mathrm{~cm} \mathrm{H}_{2} \mathrm{O}$. This pressure was small enough to avoid potentiation of Tw PDI but large enough to stop any accidental triggering of the magnet. When magnetic stimulation was triggered by the expiratory pressure the Tw PM waveforms closely resembled the Tw PoEs pressure traces, and in the study all traces were suitable for analysis.

In the present study two patients had a sniff PDI at the lower normal limit but with normal twitch pressures. A probable explanation is that they did not fully activate their diaphragm during the sniff manoeuvre. This demonstrates the relative benefit of non-volitional testing versus volitional sniff PDI which requires full cooperation from the subject.

In summary, Tw PM measured by the technique described reflects Tw POES and Tw PDI in normal subjects and patients without lung disease. The method avoids the need for an oesophageal or gastric balloon. Values of Tw $\mathrm{PM}$ over $10 \mathrm{~cm} \mathrm{H}_{2} \mathrm{O}$ make it unlikely that there is a clinically important weakness of the diaphragm (fig 4). If lower values are obtained it may be necessary to carry out further investigations including measurement of Tw PDI and sniff PDI. It should be noted, however, that we have not studied patients with lung disease, and airways obstruction in particular, which might be expected to obscure the relation between Tw PM and Tw Poes.

We conclude that $T W P_{M}$ in response to magnetic stimulation of the phrenic nerves at FRC is a promising method for the noninvasive and non-volitional evaluation of diaphragm strength in normal subjects and patients without lung disease.

C-HH is supported by a grant from the Swedish National Association for Heart and Lung Diseases.

1 Bellemare F, Bigland-Ritchie B. Assessment of human diaphragm strength and activation using phrenic nerve stimulation. Respir Physiol 1984;58:263-77.

2 Mier A, Brophy C, Moxham J, Green M. Phrenic nerve stimulation in normal subjects and in patients with diaphragmatic weakness. Thorax 1987;42:885-8.

3 Milic-Emili J, Mead J, Turner JM, Glauser EM. Improved technique for estimating pleural pressure from esophageal balloons. $\mathcal{F}$ Appl Physiol 1964;19:1101-6.

4 Yan S, Gauthier AP, Similowski T, Macklem PT, Bellemare F. Evaluation of human diaphragm contractility using mouth

5 Wragg S, Hamnegård C, Kyroussis D, Road J, Green M, Moxham J. Potentiation of diaphragmatic twitch after voluntary contraction in normal subjects. Thorax 1994; voluntary contraction in normal subjects. Thorax 1994;

6 Similowski T, Fleury B, Launois S, Cathala HP, Bouche P, 
Derenne JP. Cervical magnetic stimulation: a new painless method for bilateral phrenic nerve stimulation in conscious humans. F Appl Physiol 1989;67:1311-8.

7 Wragg S, Aquilina R, Moran J, Ridding M, Hamnegård $\mathrm{C}$, Green $\mathrm{M}$, et al. A comparison of cervical magnetic stimulation and bilateral percutaneous electrical stimulation of the phrenic nerves in normal subjects. Eur Respir 7 1994; 7:1788-92.

8 Black LF, Hyatt RE. Maximal respiratory pressures: normal values and relationships to age and sex. Am Rev Respir Dis 1969;99:698-702.

9 Baydur A, Pangiotis K, Behrakis K, Zin WA, Jaeger M, Milic Emili JA. A simple method of assessing the validity of the esophageal balloon technique. Am Rev Respir Dis 1982;126:788-91.

10 Barker AT, Freeston IL, Jalinous R, Jaratt JA. Magnetic stimulation of the human brain and peripheral nervous system: an introduction and the results of an initial clinical evaluation. Neurosurgery 1987;20:100-9.

11 Miller JM, Moxham J, Green M. The maximal sniff in the assessment of diaphragm function in man. Clin Sci 1985 69:91-6.

12 Sixt R, Bake B. A simple pressure calibrator. Scand $\mathcal{F}$ Clin Lab Invest 1976;36:1-2.

13 Bland JM, Altman DG. Statistical methods for assessing agreement between two methods of clinical measurement. Lancet 1986;i:307-10.

14 Mador MJ, Magalang UJ, Kufel TJ. Twitch potentiation following voluntary diaphragmatic contraction. $A m \mathcal{f} R e-$ spir Crit Care Med 1994;149:739-43.

15 Similowski T, Gauthier AP, Yan S, Macklem PT, Bellemare F. Assessment of diaphragm function using mouth pressure twitches in chronic obstructive pulmonary disease patients. Am Rev Respir Dis 1993;147:850-6. 